Gut, 1979, 20, 98-101

\title{
Impaired pancreatic polypeptide release in chronic pancreatitis with steatorrhoea
}

\author{
T. E. ADRIAN, H. S. BESTERMAN, C. N. MALLINSON, C. GARALOTIS, AND \\ S. R. BLOOM
}
From the Department of Medicine, Royal Postgraduate Medical School, London, and the Gastrointestinal Unit, Greenwich District Hospital, London

SUMMARY Pancreatic polypeptide (PP) is a newly discovered hormonal peptide localised in a distinct endocrine cell type in the pancreas. PP circulates in plasma and in normal subjects levels rise substantially on the ingestion of food (mean rise $138 \mathrm{pmol} / \mathrm{l}$ ). In 10 patients with chronic pancreatitis with exocrine deficiency the PP response to a test breakfast was greatly reduced (mean rise $20 \mathrm{pmol} / \mathrm{l}, \mathrm{P}<0.001$ ). PP response to the meal was normal in 10 patients with active coeliac disease and 12 patients with acute tropical sprue with steatorrhoea.

Pancreatic polypeptide (PP) is a recently discovered hormonal peptide which is localised both in the islets and between the acinar cells of the exocrine parenchyma of the pancreas in man (Larsson et al., 1976, Polak et al., 1976). The pattern of PP release after the ingestion of food closely resembles that of pancreatic enzymes and it is potently stimulated by both the vagus and gastrointestinal hormones (Adrian et al., 1976, 1977. Schwartz et al., 1976). In man it has recently been suggested that PP may play some role in the regulation of biliary and pancreatic secretion (Greenberg et al., 1977, 1978). In view of the pancreatic localisation of PP and the similarity of release stimuli for PP and pancreatic enzymes, we have therefore investigated PP release in patients with chronic pancreatitis with steatorrhoea and in patients with small intestinal mucosal atrophy.

\section{Methods}

\section{SUBJECTS}

As a stimulus for PP release, a test breakfast was used consisting of two medium-sized boiled eggs, $60 \mathrm{~g}$ bread as toast, $10 \mathrm{~g}$ butter, $35 \mathrm{~g}$ marmalade, and $150 \mathrm{ml}$ unsweetened orange juice. The breakfast, which contained $18 \mathrm{~g}$ protein, $22 \mathrm{~g}$ fat, and $66 \mathrm{~g}$ carbohydrate (530 calories), was eaten by the following groups of overnight fasted subjects:

1. Twenty-two patients with chronic pancreatitis, 10 having severe chronic steatorihoea mean age 46 years range $30-85$ years and weight $58 \pm 4 \mathrm{~kg}$

Received for publication 6 September 1978 (mean \pm SEM) and 12 having clinical evidence of pancreatic disease but no overt exocrine deficiency, mean age 45 years (range 23-80 years) and weight 64 $\pm 3 \mathrm{~kg}$ (mean \pm SEM). Patients with PP antibodies resulting from insulin therapy for diabetes had to be excluded (Bloom et al., 1978).

Diagnosis of chronic pancreatitis was made on a typical clinical history and one or more of the following: the finding of $x$-ray evidence of pancreatic calcification $(n=11)$, gross ERCP abnormalities $(n=10)$, or by histological examination of biopsies obtained at laparotomy $(n=4)$. Patients categorised as having pancreatic insufficiency in addition had marked steatorrhoea, all subjects having faecal fat excretion above $50 \mathrm{mmol} /$ day (mean $116 \pm 24$ $\mathrm{mmol} /$ day) and resulting substantial weight loss of greater than $7 \mathrm{~kg}$ from their previous normal weight (mean $10 \cdot 1 \pm 1 \cdot 1 \mathrm{~kg}$ ). In those who underwent pancreatic secretion studies $(n=6)$ a trypsin excretion reduced to less than $10 \%$ of normal (DiMagno et al., 1973) was found. The incidence of diabetes mellitus, pancreatic calcification, and alcohol abuse in the patients with chronic pancreatitis is summarised in the Table.

2. Ten patients with active coeliac disease, mean age 45 years (range 29-74 years) weight $52 \pm 3 \mathrm{~kg}$ (mean \pm SEM), faecal fat $52 \pm 12 \mathrm{mmol} /$ day (mean \pm SEM). The patients classified as having coeliac disease all had a jejunal biopsy showing total or partial villous atrophy (Trier, 1973) and, after this study, all improved on a gluten-free diet.

3. Twelve with post-infective tropical malabsorption (acute tropical sprue) mean age 29 years (range 19-57 years), weight $58 \pm 3 \mathrm{~kg}$ (mean \pm SEM), 
Table Chronic pancreatitis $(n=22)$

\begin{tabular}{lll}
\hline & Without steatorrhoea & With exocrine deficiency \\
& $\mathrm{n}=12$ & $\mathrm{n}=10$ \\
\hline Diabetes & 2 & 4 \\
Calcification & 6 & 5 \\
Alcohol abuse & 5 & 4
\end{tabular}

The table shows the number of patients with diabetes mellitus, pancreatic calcification and a history of alcohol abuse in the patients with chronic pancreatitis with and without pancreatic insufficiency. Thirteen patients with chronic pancreatitis were originally studied of whom seven were diabetic. In three of these subjects, however, circulating antibodies to PP precluded measurement of the hormone.

all had steatorrhoea, faecal fat $52 \pm 10 \mathrm{mmol} /$ day and a jejunal biopsy showing partial villous atrophy (Mathan, 1973).

4. Twenty-eight normal volunteers with no history or evidence of gastrointestinal disease. The groups of patients with chronic pancreatitis, coeliac disease and tropical sprue were separately matched for age and sex with an equal number of controls.

As an additional test, eight patients with chronic pancreatitis with overt exocrine deficiency and eight normal controls were fasted overnight and given an intravenous injection over one minute of 2 Crick Harper Raper units (CHRU) secretin per kg (Boots Ltd, Nottingham).

\section{RADIOIMMUNOASSAY}

Plasma PP levels were measured by a specific and sensitive radio-immunoassay for human pancreatic polypeptide which has been described in detail elsewhere (Adrian et al., 1976). The assay is capable of detecting changes of plasma PP of $4 \mathrm{pmol} / 1$ with $95 \%$ confidence and the antisera shows no cross-reaction with other known gastrointestinal hormones.

\section{Results}

The mean fasting PP levels and the response to the breakfast in control subjects and patients with chronic pancreatitis is shown in Fig. 1. The mean fasting PP in the control group was $28 \pm 5 \mathrm{pmol} / \mathrm{l}$ (mean \pm SEM) rising to a peak of $167 \pm 25$ at 30 minutes. The patients with chronic pancreatitis and exocrine deficiency had a basal level of $18 \pm 4$ rising to $38 \pm 10$ at 30 minutes. The difference between these two groups is highly significant (at 15 and 30 minutes, $P<0.001$, at 60 minutes $P<0.025$, at 120 minutes $P<0.005$, and at 180 minutes, $P<0.01$ ). Although the mean postprandial PP levels in the controls and patients with pancreatic insufficiency were highly significantly different the separation was not complete as one patient (Z-M) had PP levels which were within the normal range. In the group with pancreatitis without pancreatic insufficiency, however, the levels were not significantly different from those of

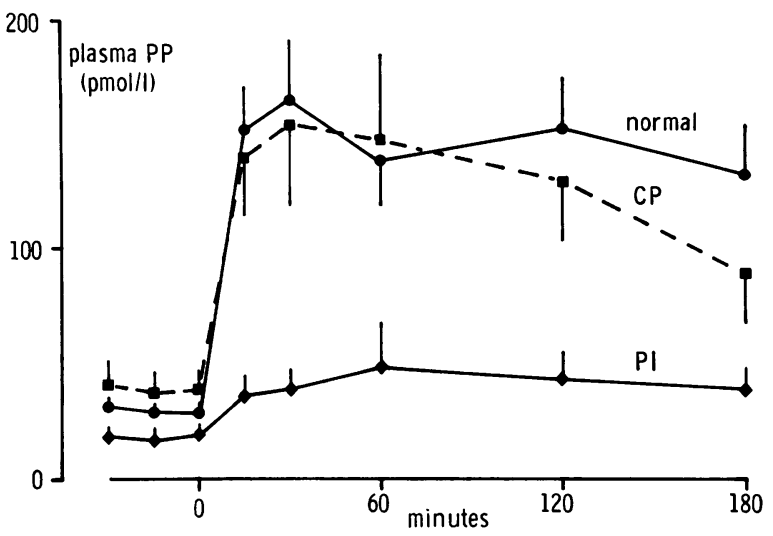

Fig. 1 Plasma PP concentrations following a test breakfast in normal subjects - patients with chronic pancreatitis and pancreatic insufficiency $(P I)$ $\checkmark$ - and patients with chronic pancreatitis with no overt exocrine deficiency $(C P) \square--\square$.

the normal subjects with a basal level of $38 \pm 10$ pmol/l rising to $155 \pm 32$ at 30 minutes.

The PP response in the 10 patients with active coeliac disease (basal) $31 \pm 10 \mathrm{pmol} / 1,30 \mathrm{~min}$ $232 \pm 36 \mathrm{pmol} / \mathrm{l}$ was also not significantly different from that of their matched normal controls (basal $29 \pm 7,30 \min 179 \pm 33$ ).

The PP response in the 12 patients with tropical sprue (basal $35 \pm 7 \mathrm{pmol} / \mathrm{l}, 30$ minutes peak $168 \pm 33$ ) was not significantly different from their matched normal controls (basal $29 \pm 9,30$ minute peak $216 \pm 68$ ).

The PP response to an intravenous injection of Boots' secretin in the control group and the patients with steatorrhoea is shown in Fig. 2. The plasma PP concentration in normal subjects rose rapidly from a basal level of $16 \pm 2 \mathrm{pmol} / \mathrm{l}$ to a peak of $122 \pm 21 \mathrm{pmol} / 1$ at six minutes and then fell rapidly to basal levels within 30 minutes. The group with chronic pancreatitis with pancreatic insufficiency, however, showed a significantly reduced response to the exogenous stimulus (basal $9 \pm 3 \mathrm{pmol} / 1$ to $47 \pm$ $22 \mathrm{pmol} / \mathrm{l}$ at six minutes $(\mathrm{P}<0.025)$. Again in the latter group patient Z-M had a rise of PP into the normal range.

\section{Discussion}

Although PP is localised almost entirely to the pancreas, a few PP cells are found in the upper alimentary tract in several species, though in man their numbers are exceedingly small (Adrian et al., 1976; Larsson et al., 1976). These cells, however, do not appear to secrete a significant amount of PP into the circulation in man, as PP is undetectable 


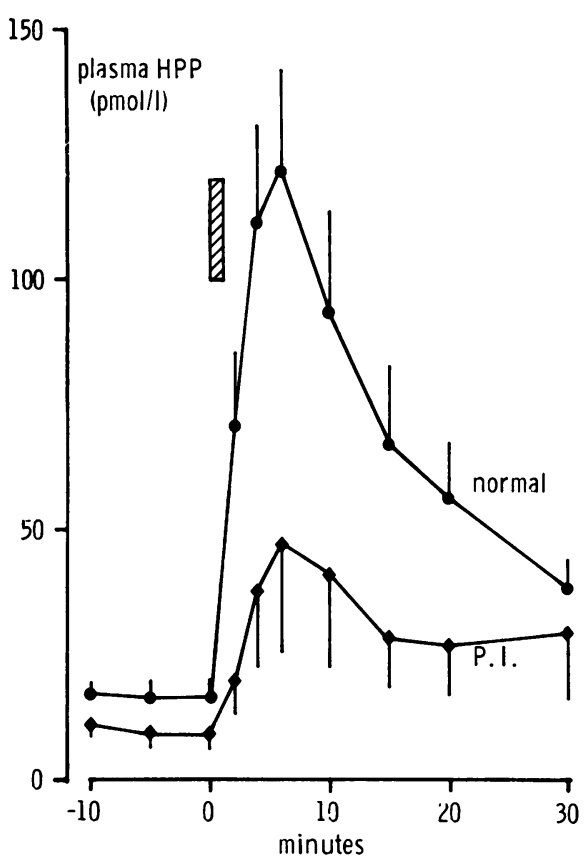

Fig. 2 Plasma PP concentration following a one minute infusion of Boots' secretin (2 Crick Harper Raper units $/ k g$ ) in normal subjects - and patients with pancreatic insufficiency due to chronic pancreatitis $(P I) \bullet-$

even postprandially in patients who have undergone pancreatectomy (Adrian et al., 1977).

PP release after a meal appears to be elicited by an entero-PP axis which is in part vagal and in part hormonal (Schwartz et al., 1976; Adrian et al., 1977). Boots' secretin, a partially purified extract of porcine intestine (containing no PP), has previously been shown to be an effective agent for PP release (Adrian et al., 1977). The use of such a stimulus by-passes the normal enteric signal mechanism and directly tests the integrity of the pancreas to secrete PP.

The observation that PP release after a meal is impaired in chronic pancreatitis with exocrine deficiency reflects the presence of steatorrhoea, an index in these patients of the extent of damage to the pancreas. The reduced PP response to Boots' secretin in these subjects may provide some further direct evidence in favour of a loss of functioning PP cells.

The normal release of PP in chronic pancreatitis without clinical steatorrhoea would suggest that effective PP cell function is maintained in spite of extensive loss of acinar cell function as steatorrhoea does not develop until exocrine secretion is reduced by $90 \%$ or more (Di Magno et al., 1973). The normal release of PP after a meal in patients with coeliac disease and tropical sprue suggests that steatorrhoea and malabsorption per se do not affect PP release. It is indeed of interest that PP release is normal in coeliac disease as pancreatic exocrine secretion after food is reported to be impaired in this condition (Worning $e t$ al., 1967; Di Magno et al., 1969; Wormsley 1970). The pancreas, however, responds quite normally to exogenous secretin and cholecystokinin and it is presumed that secretin and cholecystokinin are not released normally from the diseased small intestinal mucosa in response to acid chyme. For example, a failure of secretin release has been demonstrated (Bloom et al., 1976). It has also recently been reported that the release of GIP, another jejunal hormone is impaired in coeliac disease (Cruetzfeldt et al., 1976; Besterman et al., 1978). It is thus tempting to speculate that the humoral signal responsible for the release of PP after a meal may not be released solely from this part of the small bowel.

One patient (Z-M) with pancreatic insufficiency had a normal PP response, both to the meal and to Boots' secretin. This patient had no evidence of diabetes mellitus or pancreatic calcification and no uptake of isotope in the region of the pancreas on pancreatic scan but profound steatorrhoea and markedly reduced pancreatic exocrine secretion of bicarbonate and trypsin. ERCP showed that pancreatic ducts were normal but demonstrated the presence of a ventral pancreas. The possibility exists that the patient has a selective acinar cell loss or lipoatrophy of the pancreas. Even though steatorrhoea does not develop until pancreatic enzyme secretion is grossly impaired, release of insulin and glucagon from the pancreas in these circumstances may be surprisingly well preserved (Kalk et al., 1974). PP secretion may well give a more accurate reflection of pancreatic exocrine damage than insulin or glucagon, possibly due to the presence of a significant proportion of PP cells in the exocrine parenchyma. Morphological studies of PP cells in chronic pancreatitis would be of considerable interest.

PP measurement does not appear to be helpful in the assessment of patients with chronic pancreatitis without steatorrhoea, the group which provides the majority of diagnostic problems, or, indeed, in patients with exocrine failure, as some overlap with normal subjects occurs and other more established investigations are available. Nonetheless, the finding of a reduced PP release in pancreatic exocrine failure may be of interest in understanding the pathophysiology of this condition. 
We thank Miss W. Czaykowska for her help. Pure human pancreatic polypeptide and its antibodies were kindly donated by $\operatorname{Dr} \mathrm{R}$. E. Chance (Lilly Research Laboratories, Indianapolis). Generous support was received from the Wellcome Trust and the British Diabetic Association.

\section{References}

Adrian, T. E., Bloom, S. R., Besterman, H. S., Barnes, A. J., Cooke, T. J. C., Russell, R. C. G., and Faber, R. G. (1977). Mechanism of pancreatic polypeptide release in man. Lancet, 1, 161-163.

Adrian, T. E., Bloom, S. R., Bryant, M. G., Polak, J. M., Heitz, P., and Barnes, A. J. (1976). Distribution and release of human pancreatic polypeptide. Gut, 17, 940-944.

Besterman, H. S., Bloom, S. R., Sarson, D. L., Blackburn, A. M., Johnston, D. I., Patel, H. R., Stewart, J. S., Modigliani, R., Guerin, S., and Mallinson, C. N. (1977). Gut hormone profile in coeliac disease Lancet. 1, 785-788.

Bloom, S. R., Patel, H. R., and Johnston, D. I. (1976). Failure of secretin release in coeliac disease. (Abstract). Gut, 17, 812.

Bloom, S. R., West, A. M., Polak, J. M., Barnes, A. J., and Adrian, T. E. (1978). Hormonal contaminants of insulin. In Gut Hormones, pp. 318-322. Edited by S. R. Bloom. Churchill Livingstone: Edinburgh.

Creutzfeldt, W., Ebert, R., Arnold, R., Frerichs, H., and Brown, J. C. (1976). Gastric inhibitory polypeptide (GIP), gastrin and insulin: response to test meal in coeliac disease and after duodeno-pancreatectomy. Diabetologia, 12, 279-286.

DiMagno, E. P., Go, V. L. W., and Summerskill, W. H. J. (1969). Pancreozymin secretion is impaired in sprue. (Abstract). Gastroenterology, 56, 1149.

DiMagno, E. P., Go, V. L. W., and Summerskill, W. H. J. (1973). Relations between pancreatic enzyme outputs and malabsorption in severe pancreatic insufficiency. New England Journal of Medicine, 288, 813-815.

Floyd, J. C., Jr., Fajans, S. S., and Pek, S. (1976). Regulation in healthy subjects of the secretion of human pancreatic polypeptide, a newly recognised pancreatic islet polypeptide. Transaction of the Association of American Physicians, 89, 146-158.

Greenberg, G. R., McCloy, R. F., Björnsson, O. G., Adrian, T. E., Chadwick, V. S., Baron, J. H., and Bloom, S. R. (1978). Investigation of a physiological role for pancreatic polypeptide (PP) in man. Scandinavian Journal of Gastroenterology, 13, (Suppl. 49), 68.

Kalk, W. J., Vinik, A. I., Bank, S., Buchanan, K. D., Keller, P., and Jackson, W. P. U. (1974). Glucagon responses to arginine in chronic pancreatitis. Diabetes, 23, 257-263.

Larsson, L. I., Sundler, F., and Håkanson, R. (1976). Pancreatic polypeptide: a postulated new hormone: identification of its cellular storage site by light and electron microscopic immuno-cytochemistry. Diabetologia, 12, 211-226.

Mathan, V. I. (1973). Tropical sprue. In Gastrointestinal Disease, Pathophysiology, Diagnosis, Management, pp. 978-988. Edited by M. H. Sleisenger and J. S. Fordtran. Saunders: London.

Polak, J. M., Bloom, S. R., Adrian, T. E., Heitz, P., Bryant, M. G., and Pearse, A. G. E. (1976). Pancreatic polypeptide in insulinomas, gastrinomas, VIPomas and glucagonomas. Lancet, 1, 328-330.

Schwartz, T. W., Rehfeld, J. F., Stadil, F., Larsson, L.-I., Chance, R. E., and Moon, N. (1976). Pancreatic-polypeptide response to food in duodenal-ulcer patients before and after vagotomy. Lancet, 1, 1102-1105.

Trier, J. S. (1973). Coeliac sprue disease. In Gastrointestinal Disease, Pathophysiology, Diagnosis, Management, pp. 864-885. Edited by M. H. Sleisenger and J. S. Fordtran. Saunders: London.

Wormsley, K. G. (1970). Response to duodenal acidification in man. 3. Comparison with the effects of secretin and pancreozymin. Scandinavian Journal of Gastroenterology, 5, 353-360.

Worning, H., Müllertz, S., Thaysen, E. H., and Bang, H. O. (1967). pH and concentration of pancreatic enzymes in aspirates from the human duodenum during digestion of a standard meal in patients with intestinal disorders. Scandinavian Journal of Gastroenterology, 2, 81-89. 